\title{
Detection and antibiotic resistance of Mycoplasma gallisepticum and Mycoplasma synoviae among chicken flocks in Egypt
}

\author{
Marwa Emam ${ }^{1}$ (D), Yousreya Mohamed Hashem² (iD), Mahmoud El-Hariri ${ }^{(\mathbb{D})}$ and Jakeen El-Jakee ${ }^{3}$ (i) \\ 1. VACSERA Holding Company for Biological Products and Vaccines, Cairo, Egypt; 2. Department of Mycoplasma, Animal \\ Health Research Institute, Agriculture Research Center, Giza, Egypt; 3. Department of Microbiology, Faculty of Veterinary \\ Medicine, Cairo University, Giza, Egypt. \\ Corresponding author: Jakeen El-Jakee, e-mail: jeljakee@yahoo.com \\ Co-authors: ME: dr.memam2009@gmail.com, YMH: yousreya@gmail.com, ME: mahmoud_elhariri@cu.edu.eg \\ Received: 14-01-2020, Accepted: 26-05-2020, Published online: 23-07-2020 \\ doi: www.doi.org/10.14202/vetworld.2020.1410-1416 How to cite this article: Emam M, Hashem YM, El-Hariri M, \\ El-Jakee J (2020) Detection and antibiotic resistance of Mycoplasma gallisepticum and Mycoplasma synoviae among \\ chicken flocks in Egypt, Veterinary World, 13(7): 1410-1416.
}

\begin{abstract}
Background and Aim: Mycoplasma gallisepticum (MG) and Mycoplasma synoviae (MS) are the most significant pathogens of avian mycoplasmosis. This study aimed to isolate and identify MG and MS from chickens and detect the various virulence genes in the isolates. Moreover, the efficacies of different antibiotics were tested to identify suitable treatment regimens.

Materials and Methods: We isolated MG and MS from 487 chicken samples of different ages located in different Governorates in Egypt using conventional isolation methods. The isolates were characterized by polymerase chain reaction (PCR) and sodium dodecyl sulfate-polyacrylamide gel electrophoresis (SDS-PAGE) and then tested for antibiotic sensitivity by the minimum inhibitory concentration (MIC) method.

Results: The prevalence of MG among the isolates was $9.85 \%$, with the highest percentage isolated from air sacs, while the prevalence of MS among the isolates was $1.6 \%$. Moreover, the highest levels of the prevalence of both MG and MS were during the winter and autumn sampling, while the lowest levels were in the summer and spring. Following the $16 \mathrm{~S}$ rRNA-based detection of Mycoplasma isolates, $14 \mathrm{MG}$ and $5 \mathrm{MS}$ isolates were identified by different PCR-based detection methods for various virulence genes. Nine MG isolates contain the $m g c 2$ gene, six MG isolates contain the gap $A$ gene, and three MS isolates contain the $v l h A$ gene. We validated a duplex PCR method for the simultaneous identification of MG and MS, based on $100 \%$ of the MG and MS isolates generating common bands at 55 and $17 \mathrm{kDa}$, respectively. The MIC method identified tiamulin and spiramycin as the antibiotics of choice for the treatment of MG and MS infections, respectively.

Conclusion: For more precise diagnosis of Mycoplasma infections in chicken flocks, conventional isolation methods must be confirmed by PCR. SDS-PAGE analysis helps in epidemiological studies and vaccine preparation. The MIC method can be used to help develop therapies to control avian mycoplasmosis infections.
\end{abstract}

Keywords: $g a p A$ gene, $m g c 2$ gene, minimum inhibitory concentration, Mycoplasma infection, sodium dodecyl sulfate, $v$ lhA gene.

\section{Introduction}

Mycoplasmas are small-celled prokaryotes belonging to the class Mollicutes. They have a small genome and are unable to produce a cell wall, as well as many metabolic pathways [1]. Mycoplasma gallisepticum (MG) and Mycoplasma synoviae (MS) cause the most significant Mycoplasma infections among commercial poultry. MG infections usually lead to chronic respiratory disease (CRD) in chickens and infectious sinusitis in turkeys. MS causes subclinical upper respiratory infections, eggshell apex abnormalities, and tenosynovitis or bursitis in chickens and turkeys [2-4]. CRD caused by MG is prevalent in layer, broiler, and breeder poultry flocks. Infected birds

Copyright: Emam, et al. Open Access. This article is distributed under the terms of the Creative Commons Attribution 4.0 International License (http://creativecommons.org/licenses/by/4.0/), which permits unrestricted use, distribution, and reproduction in any medium, provided you give appropriate credit to the original author(s) and the source, provide a link to the Creative Commons license, and indicate if changes were made. The Creative Commons Public Domain Dedication waiver (http://creativecommons.org/ publicdomain/zero/1.0/) applies to the data made available in this article, unless otherwise stated. display respiratory symptoms that include sneezing, rales, coughing, as well as an exudation from the nostrils and eyes [5]. The presence of MG and MS in infected tissues or swab samples is confirmed by isolating the organisms using a specific medium or by direct detection of their DNA.

There are several types of respiratory infections that impose a significant health and economic impacts. For example, viruses and bacteria are known to coinfect chickens, although the pathogenesis involved, and their connection with mucosal surfaces are poorly described [6]. MG and MS diseases in chickens may sometimes superficially appear like respiratory diseases caused by other pathogens such as those that cause mild Newcastle disease and avian infectious bronchitis. Ishfaq et al. [7] found that MG causes CRD in chickens, and infected chickens display abnormal morphology and cellular damage, including increases in inflammatory cell infiltration, cellular debris, and exudates, and mitochondrial and DNA damage in lungs. Infections with Avibacterium paragallinarum and Pasteurella multocida may present similarly and 
should be excluded. MG in turkeys may be confused with avian pneumovirus infections, and the presence of sinusitis may also be suggestive of infections by P. multocida, Chlamydia, or MS. Moreover, care should be exercised in distinguishing between MS-related infectious synovitis, Staphylococcus aureus infections, and reovirus-related infectious tenosynovitis [8]. In general, MG and MS cause significant impacts on the poultry industry, thus detecting these pathogens is crucial for conducting epidemiological studies and control programs of avian mycoplasmosis.

This study aimed to characterize MG and MS isolates from chicken flocks using molecular methods and to test these isolates for antibiotic sensitivity by the minimum inhibitory concentration (MIC) method, thus providing a guide to optimal therapy.

\section{Materials and Methods}

\section{Ethical approval}

The study protocol was approved by Animal Ethics Committee of the Faculty of Veterinary Medicine, Cairo University, Egypt.

\section{Sampling}

We collected 487 chicken samples from different flocks, breeds, and ages in Egypt (Giza, Fayoum, Benisuef, Menya, and Alexandria) from January 2017 to July 2019.

Samples were from healthy $(n=50)$, morbid $(n=133)$, and freshly dead $(n=304)$ birds suffering from respiratory and locomotor problems.

In acute cases, tracheal swabs, synovial fluid, trachea and lung samples were collected; while in chronic stages, air sac specimens and caseous material were collected (Table-1).

\section{Culturing, isolation, and preliminary identification}

The isolation and preliminary identification of Mycoplasma isolates followed the standard procedures defined by Kleven [9]. The samples were cultured on sterile PPLO broth and agar media, as described by Frey [10]. Mycoplasma colonies were identified based on their characteristic fried egg appearance [11].

The digitonin sensitivity test was performed to differentiate between Mycoplasma and Acholeplasma isolates [12]. The glucose fermentation test [13] and the arginine hydrolysis test [14] were performed to differentiate Avian Mycoplasma species. Finally, the film and spot formation test used to identify Mycoplasma synoviae [15] and the growth inhibition test [16] were

Table-1: Type and number of the examined samples.

\begin{tabular}{lcccc}
\hline Type of sample & $\begin{array}{c}\text { Healthy } \\
\text { birds }\end{array}$ & $\begin{array}{c}\text { Morbid } \\
\text { birds }\end{array}$ & $\begin{array}{c}\text { Freshly } \\
\text { dead birds }\end{array}$ & Total \\
\hline Tracheal swab & 50 & 133 & - & 183 \\
Trachea & - & - & 63 & 63 \\
Lung & - & - & 118 & 118 \\
Air sacs & - & - & 51 & 51 \\
Caseous material & - & - & 2 & 2 \\
Synovial fluid & - & - & 70 & 70 \\
Total number & 50 & 133 & 304 & 487 \\
\hline
\end{tabular}

performed to identify a Mycoplasma isolate depending on serology.

\section{Purification and maintenance of isolates [17]}

A single fried egg-shaped colony was picked, including the agar block, and transplanted into a broth medium to obtain a pure culture. The purified isolates were kept at $-20^{\circ} \mathrm{C}$ in the form of agar blocks.

\section{Sodium dodecyl sulfate-polyacrylamide gel electro- phoresis (SDS-PAGE)}

The isolates were characterized to determine strain variability. SDS-PAGE followed the methods described by Laemmli [18]. The samples were run alongside preserved molecular weight markers ladder from Cleaver Scientific Ltd (Blue Wide Range Prestained Protein Ladder, UK) and low molecular weight protein ladder (Pharmacia Biotech, USA). $200 \mu \mathrm{l}$ of activated MG or MS Broth culture was mixed with equal volume of denaturation mixture containing 2-mercaptoethanol. The mixture was boiled for $5 \mathrm{~min}$ then $20 \mu 1$ was applied to each well of the SDS-PAGE gel. The gel was run at a constant power of $25 \mathrm{~mA}$ for approximately $4-5 \mathrm{~h}$ using a horizontal electrophoresis connected with power supply (Biometra, USA). Low molecular weight and wide range protein ladders were included in each run. The gel was stained overnight (50\% methanol, $7 \%$ glacial acetic acid, and $0.2 \%$ Coomassie Brilliant Blue) and de-stained using a solution containing $40 \%$ methanol and $7 \%$ glacial acetic acid. The bands were visualized, photographed, and analyzed using Alpha View-AlphaImager HP (ProteinSimple, CA, USA).

\section{Polymerase chain reaction (PCR)}

DNA of each isolate was extracted using the Quick-DNA $^{\mathrm{TM}}$ Universal Kit catalog no D4068 and D4069 (Qiagen, USA. PCR was conducted using specific primers and amplification cycles according to the references as shown in Table-2 [8,19-22]. Aliquots $(10 \mu \mathrm{l})$ from each reaction mixture were analyzed by electrophoresis ( 1.5 volts, $45 \mathrm{~min})$ using $1.5 \%$ (weight/volume) agarose in $1 \times \mathrm{TBE}$ (Tris, boric acid, EDTA, pH 8.0). After electrophoresis, gels were stained with ethidium bromide $(1 \mu \mathrm{l} / \mathrm{gel})$ and visualized and photographed with an ultraviolet transilluminator and camera system [23].

\section{Microbroth antibiotic sensitivity testing}

MG and MS isolates were treated with a range of concentrations $(64 \mu \mathrm{g} / \mathrm{ml}-0.0625 \mu \mathrm{g} / \mathrm{ml})$ of the following antibiotics: Ciprofloxacin $100 \mathrm{mg} / \mathrm{ml}$ (Agrovetica Egypt), doxycycline $100 \mathrm{mg} / \mathrm{ml}$ (Primavet, Egypt), linco spectinomycin (lincomycin $50 \mathrm{mg} / \mathrm{ml}$ and spectinomycin $100 \mathrm{mg} / \mathrm{ml}$ ) (Delta Pharma, Egypt), oxytetracycline $30 \mathrm{mg} / \mathrm{ml}$ (Pfizer, Egypt), spiramycin 150,000,000 IU (Merial, France), tiamulin $450 \mathrm{mg} / \mathrm{g}$ (Novartis, Switzerland), tilmicosin 25\% (Atco Pharma, Egypt), and tylosin $200 \mathrm{mg}$ base/ml (Adwya, Egypt). The experiment was designed to determine the lowest concentration that completely prevents microbial growth, as described by Hannan [24]. 


\section{Results}

\section{Occurrence of Mycoplasma isolates in the samples}

Table-3 shows that MG was isolated from $9.85 \%$ of the samples consisting of tracheal swabs, trachea, lung, air sacs, and caseous materials. Meanwhile, MS was isolated only from the synovial fluid (1.6\%). The results clearly show that the highest incidence of Mycoplasma infections occurs during winter.

\section{SDS-PAGE}

The MG isolates; $60 \%$ (5/9 isolates) shared bands at 73, 72, 56, 53, 47, 46, and $24 \mathrm{kDa} ; 70 \%(6 / 9$ isolates) shared bands at 54 and $20 \mathrm{kDa} ; 80 \%$ (7/9 isolates) shared a $70 \mathrm{kDa}$ band; $90 \%$ (8/9 isolates) shared a $19 \mathrm{kDa}$ band; and all isolates shared a $55 \mathrm{kDa}$ band (Figure-1:1.1).

The MS isolates; $60 \%$ (3/5 isolates) shared bands at $72,30,27,25$, and $22 \mathrm{kDa} ; 80 \%$ (4/5 isolates) shared 37 and $20 \mathrm{kDa}$ bands; and all of the isolates shared a $17 \mathrm{kDa}$ band (Figure-1).

PCR

In PCR analysis of 16 Mycoplasma isolates was analyzed by PCR to specifically amplify the $16 \mathrm{~S}$ rRNA gene. Only 14 isolates were identified as MG, while the $m g c 2$ and gapA virulence gene was detected in only nine and six of the $14 \mathrm{MG}$ isolates, respectively.

Five Mycoplasma isolates were analyzed by PCR. Based on their 16S rRNA gene, all five isolates are classified as MS. The $v$ lhA virulence gene was detected in only three out of five MS isolates.

Duplex PCR analysis was designed to simultaneously detect $\mathrm{MG}$ and MS by targeting the $16 \mathrm{~S}$ $23 \mathrm{~S}$ rRNA gene region of the isolates. MG positive results were 14/16 (87.5\%). 14 MG OIE positive isolates were tested for virulence using $m g c 2$ virulent gene and $\operatorname{gap} A$ virulent gene and we found that $9 / 14$ were $m g c 2$ positive isolates $(64.3 \%)$ and $6 / 14$ were gapA positive isolates (42.9\%) (Figure-2). MS positive results were $5 / 5(100 \%)$. MS OIE positive isolates were tested for virulence using $v / h A$ virulent and we found $3 / 5$ were $v \operatorname{lh} A$ gene-positive isolates $(60 \%)$ (Figure-3). Results indicated a difference in virulence between the isolates. Finally, we adopted and validated duplex PCR for simultaneous identification of $\mathrm{MG}$ and $\mathrm{MS}$ as it was more rapid and cheaper method in comparison to single PCR for identification of $\mathrm{MG}$ and MS.
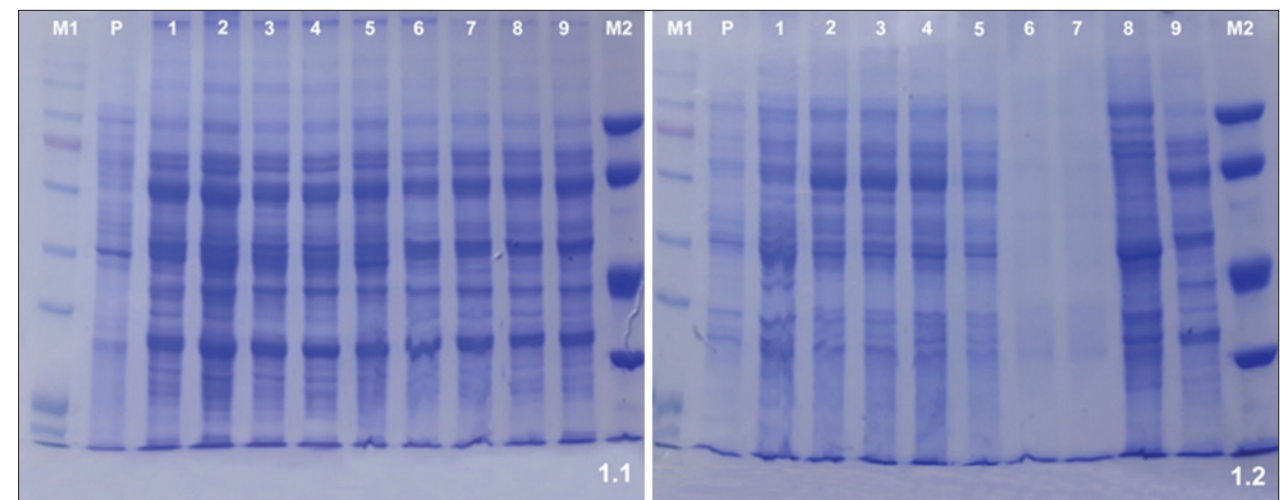

Figure-1: Sodium dodecyl sulfate (SDS)-polyacrylamide gel electrophoresis among Mycoplasma isolates. 1.1): SDSPolyacrylamide gel electrophoresis among MG isolates. Lane M1: A high molecular weight marker, lane P: Reference strain, lanes 1-9: Mycoplasma gallisepticum isolates and Lane M2: Low molecular weight marker.1.2): SDS-polyacrylamide gel electrophoresis among MS isolates. Lane M1: High molecular weight marker. Lane P: Reference strain, lanes 1-9: Mycoplasma synoviae isolates (Lane 1 and 9 [first MS isolate] Lane 2 and 3 [second MS isolate] Lane 4 and 5 [Third MS isolate] Lane 6 and 7 [fourth MS isolate] Lane 8 [fifth MS isolate]) and Lane M2: Low molecular weight markers.

Table-2: Primers used for PCR analysis.

\begin{tabular}{|c|c|c|c|c|}
\hline Microorganism & Gene & Primer 5'- 3' & Amplicon size & Reference \\
\hline \multirow[t]{3}{*}{$\begin{array}{l}\text { Mycoplasma } \\
\text { gallisepticum }\end{array}$} & $16 \mathrm{~S}$ rRNA & $\begin{array}{l}\text { F-GAG-CTA-ATC-TGT-AAA-GTT-GGT-C } \\
\text { R-GCT-TCC-TTG-CGG-TTA-GCA-AC }\end{array}$ & $185 \mathrm{bp}$ & [8] \\
\hline & $m g c 2$ & $\begin{array}{l}\text { F-CGCAATTTGGTCCTAATCCCCAACA } \\
\text { R-TAAACCCACCTCCAGCTTTATTCC }\end{array}$ & 300 bp & [20] \\
\hline & gapA & $\begin{array}{l}\text { F-GCCGGA TTG ATT TGT ATG } \\
\text { R-ACT TGT TIT GTG TTT CC }\end{array}$ & $1511 b p$ & [21] \\
\hline \multirow[t]{2}{*}{$\begin{array}{l}\text { Mycoplasma } \\
\text { synoviae }\end{array}$} & $16 \mathrm{~S}$ rRNA & $\begin{array}{l}\text { F-GAG-AAG-CAA-AAT-AGT-GAT-ATC-A } \\
\text { R-CAG-TCG-TCT-CCG-AAG-TTA-ACA-A- }\end{array}$ & 207 bp & {$[8]$} \\
\hline & VIhA & $\begin{array}{l}\text { F-GTACGGTGTTAAGTCATC } \\
\text { R-CGTATTTACAGCACCAGTAGTAACT }\end{array}$ & $1100 \mathrm{bp}$ & {$[22]$} \\
\hline \multirow[t]{2}{*}{ Both (Duplex) } & MG: IGSR (16S-23S rRNA) & $\begin{array}{l}\text { F-GTAGGGCCGGTGATTGGAGTTA } \\
\text { R-CCCGTAGCATTTCGCAGGAGTTA }\end{array}$ & $812 b p$ & [23] \\
\hline & MS: $16 S$ rRNA & $\begin{array}{l}\text { F-GAGAAGCAAAATAGTGATATCA } \\
\text { R-CAGTCGTCGTCTCCGAAGTTAACAA }\end{array}$ & 207bp & [8] \\
\hline
\end{tabular}

PCR: Polymerase chain reaction 


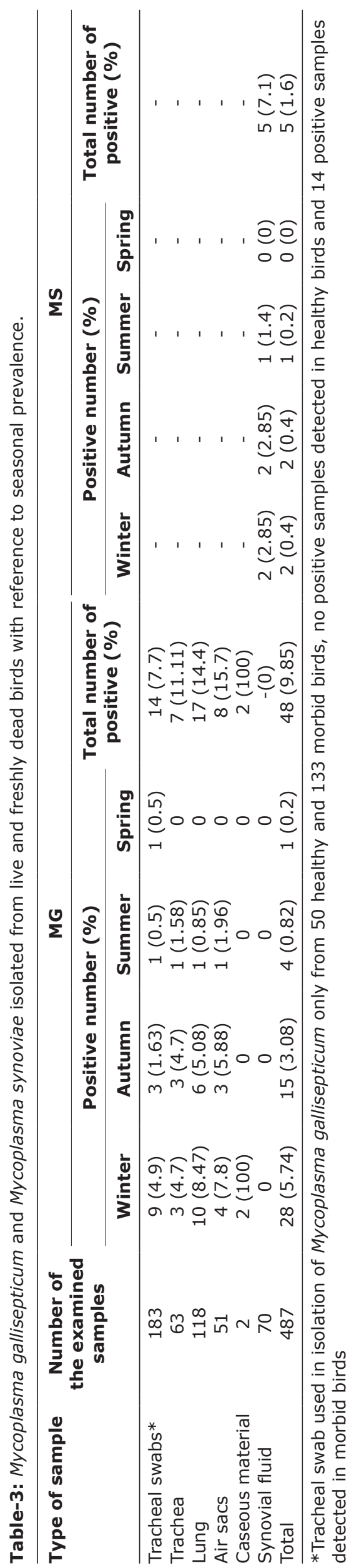

\section{Microbroth antibiotic sensitivity test}

Antimicrobial sensitivity tests were conducted on $5 \mathrm{MG}$ and $3 \mathrm{MS}$ isolates using the MIC method (Table-4). The MIC values among the isolates ranged from 0.0625 to $0.5 \mathrm{ug} / \mathrm{ml}$.

\section{Discussion}

MG and MS are important pathogens that affect poultry worldwide, causing enormous economic losses in the poultry industry $[25,26]$.

MG is a major poultry pathogen [27] that causes CRD in chickens and turkeys and also negatively impacts egg hatchability and development [28]. MG infections also affect virus titers and the efficacy of some poultry viral vaccines [29,30]. In our study, analysis of tracheal swabs, trachea, lungs, and air sac samples showed that MG is most prevalent in the air sacs $(15.7 \%)$, a result that is similar to that reported by Reda and El-Samie [31] and and Mohamed [32], who isolated $\mathrm{MG}$ from air sacs at the highest rates of $23.3 \%$ and $21.5 \%$ respectively. Meanwhile, EI-Jakee et al. [33] isolated and cultured 14 Mycoplasma isolate from tracheal swabs collected from 12 broiler breeder flocks.

Necropsy of the diseased birds revealed chronic macroscopic lesions accumulating as caseous material in the lungs [34]. This material is sticky, attaching to the respiratory surface of the air sacs. All of the MG isolates in our study were obtained from caseous material.

MS is an important poultry pathogen that causes air sacculitis, synovitis, and reduced egg production, resulting in great economic losses [4,35]. The prevalence of MS in the synovial fluid was only $7.1 \%$. This low percentage is attributed to the difficulty in isolating MS due to its fastidious growth.

MG and MS were digitonin positive, glucose fermentation positive, and arginine hydrolysis negative. Meanwhile, only suspected MS isolates gave positive results in the film and spot assay. In the growth inhibition test, $85 \%$ of suspected MG isolates were inhibited by specific antiserum against $\mathrm{MG}$, while all MS isolates were inhibited by anti-MS antiserum. These results agree well with the results of biochemical identification.

The present study shows that MG and MS infections are more predominant during winter and autumn compared to summer and spring. This seasonal difference is probably due to poor temperature control measures, resulting in low-temperature stress [36].

SDS-PAGE has been used to demonstrate minor but distinct and reproducible differences in protein patterns among strains of MG and MS. Therefore, SDS-PAGE is a useful procedure in epidemiological and other studies, where it is important to be able to distinguish between bacterial strains based on protein patterns. The molecular detection of pathogenic isolates of MG by SDS-PAGE was indicated by the presence of specific 72 and $73 \mathrm{kDa}$ bands in $60 \%$ 


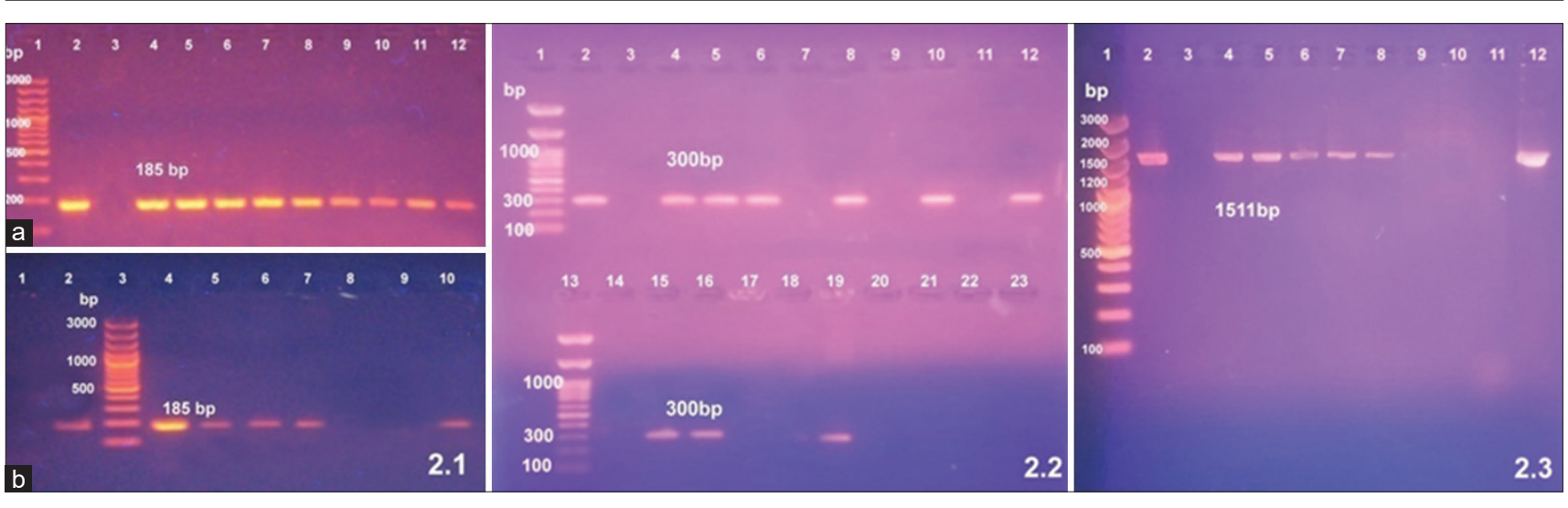

Figure-2: Results for polymerase chain reaction (PCR) for the detection of $16 \mathrm{~S}$ rRNA, mgc2, and gapA genes among the isolates. 2.1): Agarose gel electrophoresis of amplified PCR products of $16 \mathrm{~S}$ rRNA gene among Mycoplasma gallisepticum at 185 bp. (a): Lane 1: 100 bp DNA marker (Thermo Fisher Scientific, USA), lane 2: Positive control, lane 3: Negative control, lanes: 4-12: MG positive isolates. (b): Lane 1: Negative control, lane 2: Positive control, lane 3:100 bp DNA marker (Thermo Fisher Scientific, USA), lanes 4-7 and 10: MG positive isolates. Lanes 8 and 9: Negative M. gallisepticum isolates. 2.2): Agarose gel electrophoresis of amplified PCR products of $m g c 2$ gene of $M$. gallisepticum isolates at 300 bp. Lanes 1 and 13: 100 bp DNA marker (Gene Direx, USA), Lane 2: Positive control, Lanes 3 and 14: Negative control, Lanes 4, 5, 6, 8, 10, 12, 15, 16, and 19: Positive M. gallisepticum (mgc2 gene) isolates and lanes 7, 9, 11, 17, and 18: Negative M. gallisepticum (mgc2 gene) isolates. 2.3): Agarose gel electrophoresis of amplified - PCR products of gapA gene of $M$. gallisepticum isolates at 1511 bp. Lane 1: 100 bp DNA marker (Thermo Fisher Scientific, USA), Lane 2: Positive control, Lane 3: Negative control, Lanes 4, 5, 6, 7, 8, and 12: Positive M. gallisepticum (gapA gene) isolates and lanes 9, 10, and 11: Negative M. gallisepticum (gapA gene) isolates.

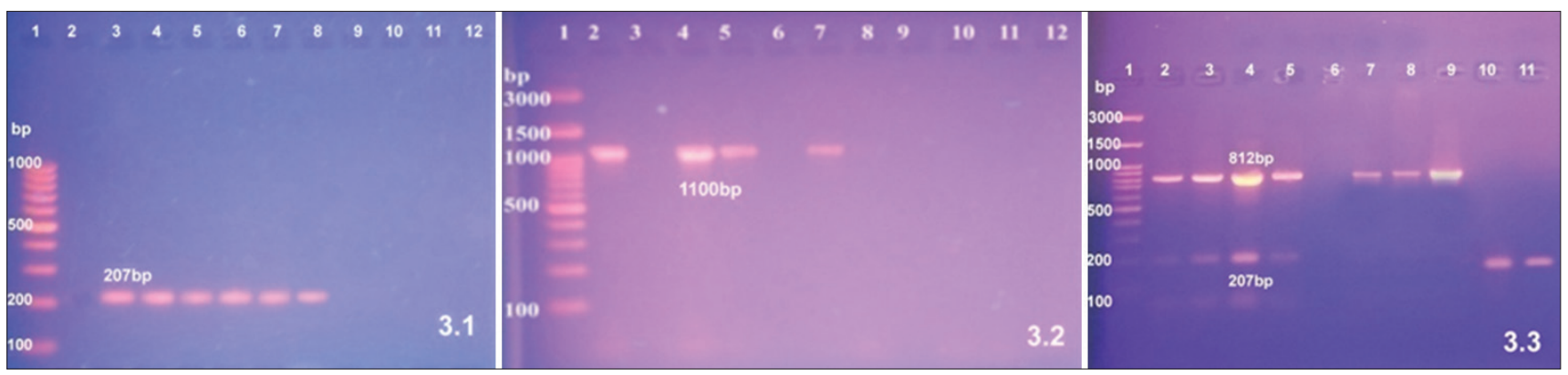

Figure-3: Results for polymerase chain reaction (PCR) for the detection of $16 \mathrm{~S}$ rRNA, vlhA, and 16S-23S rRNA genes among the isolates. 3.1): Agarose gel electrophoresis of amplified PCR products of rRNA16S rRNA gene of among Mycoplasma synoviae isolates at 207 bp. Lane 1: 100 bp DNA marker (Thermo Fisher Scientific, USA), lane 2: Negative control, lane 3: Positive control, lanes 4 to 8: Positive MS isolates. 3.2): Agarose gel electrophoresis of amplified PCR products among v/hA gene of M. synoviae isolates at 1100 bp. Lane 1: 100 bp DNA marker (Gene Direx), Lane 2: Positive control, Lane 3: Negative control, Lanes 4, 5 and 7: Positive M. synoviae ( $(\mathrm{l} / \mathrm{hA}$ gene) isolates and Lanes 6 and 8: Negative M. synoviae ( $\mathrm{Vlh} A$ gene) isolates. 3.3): Agarose gel electrophoresis of amplified PCR products of both 16S-23S rRNA gene among Mycoplasma gallisepticum (MG) and M. synoviae. Lane 1: 100 bp DNA marker (Thermo Fisher Scientific, USA), Lanes 2-4: Showing amplification of 812 and 207 bp products of MG and MS, respectively, Lane 5: Positive MS strain Lane 6: Negative control, Lanes 7-9: Showing amplification of 812 bp product of MG, Lanes 10 and 11: Showing amplification $n$ of 207 bp product of MS.

Table-4: Microbroth antibiotic sensitivity test (minimum inhibitory concentration).

\begin{tabular}{lcccccccccc}
\hline Antimicrobial & \multicolumn{4}{c}{ Isolates (MG) } & \multicolumn{2}{c}{ Range } & \multicolumn{3}{c}{ Isolates (MS) } & Range \\
\hline Ciprofloxacin & 0.0625 & 0.0625 & 0.125 & 0.0625 & 0.0625 & $0.0625-0.125$ & 0.0625 & 0.0625 & 0.125 & $0.0625-0.125$ \\
Doxycycline & 0.25 & 0.0625 & 0.125 & 0.0625 & 0.0625 & $0.0625-0.25$ & 0.5 & 0.125 & 0.125 & $0.125-0.5$ \\
Lincospectin mycin & 0.0625 & 0.25 & 0.125 & 0.0625 & 0.0625 & $0.0625-0.25$ & 0.25 & 0.125 & 0.125 & $0.125-0.25$ \\
Oxytetracycline & 0.0625 & 0.25 & 0.25 & 0.0625 & 0.125 & $0.0625-0.25$ & 0.0625 & 0.125 & 0.125 & $0.0625-0.125$ \\
Spiramycin & 0.0625 & 0.25 & 0.25 & 0.125 & 0.125 & $0.0625-0.25$ & 0.0625 & 0.0625 & 0.0625 & 0.0625 \\
Tiamulin & 0.0625 & 0.0625 & 0.0625 & 0.0625 & 0.0625 & 0.0625 & 0.5 & 0.25 & 0.0625 & $0.0625-0.5$ \\
Tilmicosin & 0.0625 & 0.125 & 0.5 & 0.0625 & 0.0625 & $0.0625-0.5$ & 0.25 & 0.125 & 0.0625 & $0.0625-0.25$ \\
Tylosin & 0.0625 & 0.5 & 0.25 & 0.125 & 0.0625 & $0.0625-0.5$ & 0.5 & 0.125 & 0.0625 & $0.0625-0.5$ \\
\hline
\end{tabular}

MS=Mycoplasma synoviae, $\mathrm{MG}=$ Mycoplasma gallisepticum

of the isolates, which was also observed by Hassan et al. [36].

Strategies to control MG and MS infections are based primarily on serological and/or bacteriological screening. However, culture-based methods are laborious, time-consuming and may fail to detect Mycoplasma species from medicated birds. They are also less sensitive than PCR-based methods. PCR provides a rapid, sensitive, and precise method for diagnosing MG from suspected cases [5]. 
MG and MS isolated from chicken flocks were biochemically tested and then identified using PCR. Targeting using the 16S rRNA gene, PCR positively identified $87.5 \%$ and $100 \%$ of the MG and MS isolates, respectively. This finding agrees with those of Atique et al. [37] who confirmed that PCR provides more reliable, specific, and rapid results compared to culture.

The isolates that were positive for the $m g c 2$ and gapA genes accounted for $64.3 \%$ and $42.9 \%$ of the MG OIE-positive isolates. The isolates that were positive for the $v l h$ gene accounted for $60 \%$ of the MS OIE-positive isolates. These results suggest that the isolates may differ in their respective virulence levels. Therefore, Norouzian et al. [38] highlighted the importance of understanding the relationship between changes in $\mathrm{MG}$ antigenicity and pathogenicity to genetic variations.

Duplex PCR is cheaper and faster than single PCR for the identification of MG and MS. It is, therefore a good alternative method. The duplex technique was able to detect MG and MS simultaneously, although the MG bands are more intense than those of MS [39]. In our study, we adopted and validated duplex PCR for the simultaneous identification of MG and MS.

The PCR technique not only has several advantages, but it is also limited by the development of severe contamination due to the improper handling of samples, thus resulting in false-positive results $[40,41]$. Therefore, conventional cultural methods should be carried out in parallel with PCR.

Abd El-Hamid et al. [42] demonstrated that MG and MS infections can be controlled by proper treatment procedures. To develop an effective antibiotic treatment for MG and MS infections, we performed MIC experiments using eight different antimicrobials against five and three different MG and MS field isolates, respectively. On the one hand, tiamulin was the most effective antimicrobial for inhibiting MG growth in vitro. Thus, we recommend treating MG-infected birds using this antimicrobial, which agrees with Xiao et al. [43], who concluded that tiamulin is highly active against MG. On the other hand, spiramycin was the most effective antimicrobial for inhibiting the growth of MS in vitro. The use of this antibiotic has not yet resulted in any case of mycoplasma resistance; thus, we recommend it for treating MS infection. Hong et al. [44] suggested treating MS infections with antibiotics that do not cause the rapid development of MS resistance.

\section{Conclusion}

MG and MS are the predominant species of Mycoplasma that causes respiratory and joint problems in chickens in the different Egyptian governorates (Giza, Fayoum, Benisuef, Menya, and Alexandria). Although time-consuming, the traditional cultural approach remains the gold standard for MG and MS diagnosis. PCR-based methods are more specific and faster than traditional culture-based methods; however, they should be performed in parallel with the traditional culture-based method. Periodic in vitro testing of MICs of antibiotics against Mycoplasma field isolates is required to monitor the impact of mass medication programs and to assist in developing effective therapies.

\section{Authors' Contributions}

ME collected the data, participated in the design of the work protocol, performed the laboratory work, and was involved in the preparation of the manuscript. $\mathrm{ME}$ and $\mathrm{YMH}$ found the research idea, shared in the performed data and designed the work protocol. JE participated in the design of the work protocol, contributed to the manuscript review and interpreted the results. All authors were involved in the preparation of the manuscript and had read and approved the final manuscript.

\section{Acknowledgments}

We would like to express our deep gratitude to Microbiology Department, Faculty of Veterinary Medicine, Cairo University and Mycoplasma Department, Animal Health Research Institute, Agriculture Research Center for continuous support in our study. The authors did not receive any funds for this study.

\section{Competing Interests}

The authors declare that they have no competing interests.

\section{Publisher's Note}

Veterinary World remains neutral with regard to jurisdictional claims in published institutional affiliation.

\section{References}

1. Semashko, T.A., Arzamasov, A.A., Fisunov, G.Y. and Govorun, V.M. (2017) Transcription profiling data set of different states of Mycoplasma gallisepticum. Genom. Data, 11(1): 49-54.

2. Mettifogo, E., Buzinhani, M., Buim, M.R., Timenetsky, J. and Ferreira, A.J.P. (2015) Evaluation of a PCR multiplex for detection and differentiation of Mycoplasma synoviae, M. gallisepticum, and M. gallisepticum strain F-vaccine. Pesq. Vet. Bras., 35(1): 13-18.

3. Prajapati, A., Subhashree, N., Siju, S.J., Yogisharadhya, R. and Patil, S.S. (2018) Prevalence of Mycoplasma gallisepticum and Mycoplasma synoviae in poultry-India Perspective. Int. J. Curr. Microbiol. Appl. Sci., 7(5): 2213-2220.

4. Koutoulis, K.C., Kefalas, G., Mouttotou, N., De Gussem, K. and Theodosiou, D. (2013) Efficacy of tylosin tartrate on Mycoplasma infections and Eggshell Apex Abnormalities in layer hens under field conditions. Am. J. Anim. Vet. Sci., 8(4): 246-252.

5. Gondal, M.A., Rabbani, M., Muhammad, K., Yaqub, T., Babar, M.E., Sheikh, A.A. and Khan, M.I. (2015) Characterization of Mycoplasma gallisepticum isolated from commercial poultry flocks. J. Anim. Plant Sci., 25(1): 108-113.

6. Sid, H., Hartmann, S., Petersen, H., Ryll, M. and Rautenschlein, S. (2016) Mycoplasma gallisepticum modifies the pathogenesis of influenza a virus in the avian tracheal epithelium. Int. J. Med. Microbiol., 306(3): 174-186.

7. Ishfaq, M., Zhang, W., Shah, S.W.A., Wu, Z., Wang, J., Ding, L. and Li, J. (2020) The effect of Mycoplasma gallisepticum infection on energy metabolism in chicken lungs: Through oxidative stress and inflammation. Microb. 
Pathog., 138: 103848.

8. OIE. (2008) Avian mycoplasmosis (Mycoplasma gallisepticum, Mycoplasma synoviae). In OIE Terrestrial Manual, Ch. 2.3.5. OIE, Paris. p482-495.

9. Kleven, S.H. (1998) Mycoplasmas in the etiology of multifactorial respiratory disease. Poult. Sci., 77(8): 1146-1149.

10. Frey, M.L. (1968) A medium for the isolation of avian mycoplasmas. Am. J. Vet. Res., 29(11): 2163-2171.

11. Quinn, P.J., Markey, B.K., Leonard, F.C., Hartigan, P., Fanning, S. and Fitzpatrick, E. (2011) Veterinary Microbiology and Microbial Disease. John Wiley and Sons, Hoboken, New Jersey.

12. Freundt, E.A. (1983) Culture media for classic mycoplasmas. Methods Mycoplasmol., 1: 127-135.

13. Erno, H. and Stipkovits, L. (1973) Bovine Mycoplasma. Cultural and biochemical studies. Acta Vet. Scand., 14(3): 463.

14. Fenske, J.D. and Kenny, G.E. (1976) Role of arginine deiminase in growth of Mycoplasma hominis. J. Bacteriol., 126(1): 501-510.

15. Krieg, N.R. and Holt, J.G. (1984) Bergey's Manual of Systematic Bacteriology, Vol. 1. Williams and Wilkins, Baltimore, London.

16. Clyde, W.A. (1983) Growth inhibition tests. In: Razin, S and Tully, J.G., editors. Methods in Mycoplasmology. Vol. 1. Academic Press, New York. p405-10.

17. Sabry, M.Z. (1968) Characterization and Classification of Avian Mycoplasmas. Ph.D. Thesis, Cornell University, USA. p244.

18. Laemmli, U.K. (1970) Cleavage of structural proteins during the assembly of the head of bacteriophage T4. Nature, 227(5259): 680.

19. García, M., Ikuta, N., Levisohn, S. and Kleven, S.H. (2005) Evaluation and comparison of various PCR methods for detection of Mycoplasma gallisepticum infection in chickens. Avian Dis., 49(1): 125-132.

20. Papazisi, L., Frasca, S., Gladd, M., Liao, X., Yogev, D. and Geary, S.J. (2002) GapA and CrmA co-expression is essential for Mycoplasma gallisepticum cytadherence and virulence. Infect. Immun., 70(12): 6839-6845.

21. Zhao, S. and Yamamoto, R. (1993) Detection of Mycoplasma synoviae by polymerase chain reaction. Avian Pathol., 22(3): 533-542.

22. Raviv, Z., Ferguson-Noel, N., Laibinis, V., Wooten, R. and Kleven, S.H. (2007) Role of Mycoplasma synoviae in commercial layer Escherichia coli peritonitis syndrome. Avian Dis., 51(3): 685-690.

23. Sambrook, J., Fritsch, E.F. and Maniatis, T. (1989) Molecular Cloning: A Laboratory Manual. $2^{\text {nd }}$ ed. Cold Spring Harbor Laboratory Press, New York.

24. Hannan, P.C. (2000) Guidelines and recommendations for antimicrobial minimum inhibitory concentration (MIC) testing against veterinary Mycoplasma species. Vet. Res., 31(4): 373-395.

25. Zahoor, M.A., Nawaz, Z., Siddique, A.B., Rahman, S.U. and Ali, S. (2017) Simultaneous detection of Mycoplasma infections in clinically sick and apparently healthy broilers. Vet. Sci. Res. Rev., 3(2): 34-37.

26. Rajkumar, S., Reddy, M.R. and Somvanshi, R. (2018) Molecular prevalence and seroprevalence of Mycoplasma gallisepticum and M. synoviae in Indian poultry flocks. $J$. Anim. Res., 8(1): 15-19.

27. Ron, M., Gorelick-Ashkenazi, A., Levisohn, S., Nir-Paz, R. Geary, S.J., Tulman, E. and Yogev, D. (2015) Mycoplasma gallisepticum in vivo induced antigens expressed during infection in chickens. Vet. Microbiol., 175(2-4): 265-274.

28. Zhang, F., Bao, S., Yu, S., Cheng, J., Tan, L., Qiu, X.S. and Ding, C. (2015) Development of a loop-mediated isothermal amplification targeting a gene within the pyruvate dehydrogenase complex, the $p d h A$ gene, for rapid detection of Mycoplasma gallisepticum. J. Vet. Diagn. Investig., 27(3): 260-267.

29. Fathy, M., El-safty, M.M., El-Jakee, J.K., ABbd-alla, H.I. and Mahmoud, H. (2017) Study the effect of Mycoplasma contamination of eggs used in virus titration and efficacy of some live attenuated poultry viral vaccines. Asian J. Pharm. Clin. Res., 10(1): 216-222.

30. Fathy, M., El-Safty, M.M., Abd-Alla, H.I., Ibrahim, M.A., Ashfaq, M.K. and El-Jakee, J. (2019) Mycoplasma gallisepticum infection and efficacy of inactivated poultry viral vaccines. J. Glob. Pharm. Technol., 11(6): 145-154.

31. Reda, L.M. and El-Samie, L.A. (2012) Some studies on the diagnosis of Mycoplasma gallisepticum in chicken. Lung, 26(180): 14-4.

32. Mohamed, Z. R. (1997) Some studies on Mycoplasma gallisepticum in broiler chickens in Egypt. M.V.Sc. Thesis. (Poultry and Rabbit Diseases) Faculty of Veterinary Medicine, Zagazig University, Egypt.

33. EI-Jakee, J., Marouf, S.H., Amin, B.H. and Hedia, R.H. (2019) Characterization of mycoplasmae isolated from chicken. Biosci. Res., 16(2): 1843-1853.

34. Kleven, S.H. (2008) Control of avian Mycoplasma infections in commercial poultry. Avian Dis., 52(3): 367-374.

35. Shahid, M.A., Marenda, M.S., Markham, P.F. and Noormohammadi, A.H. (2014) Development of an oriC vector for use in Mycoplasma synoviae. J. Microbiol. Methods, 103: 70-76.

36. Hassan, S., Mukhtar, N., Rahman, S.U. and Mian, A.A. (2014) Molecular epidemiology of Mycoplasma gallisepticum in different types of chickens. Int. J. Agric. Biol., 16(1): 166.

37. Atique, M.A., Abbas, F., Tariq, M.M., Babar, S., Awan, M.A., Ali, I. and Bokhari, F.A. (2017) Biological identification of Mycoplasma gallisepticum causing respiratory problems in layer flocks in Quetta district of Balochistan. Pure Appl. Biol., 6(4): 1487-1493.

38. Norouzian, H., Farjanikish, G. and Hosseini, H. (2019) Molecular characterisation of Mycoplasma gallisepticum isolates from Iran in the period 2012-2017. Acta Vet. Hung., 67(3): 347-359.

39. Malekhoseini, G., Pourbakhsh, S.A., Homayounimehr, A.R., Zolfeghari, M.R., Ashtari, A. and Abtin, A.R. (2017) Simultaneous identification of Mycoplasma gallisepticum and Mycoplasma synoviae by duplex PCR assay. Immunol. Case Rep., 1(1): 12-16.

40. OIE. (2000) Manual of Standards for Diagnostic Tests and Vaccines. Office International Des Epizooties, Paris, France.

41. Salisch, H., Ryll, M., Hinz, K.H. and Neumann, U. (1999) Experiences with multispecies polymerase chain reaction and specific oligonucleotide probes for the detection of Mycoplasma gallisepticum and Mycoplasma synoviae. Avian Pathol., 28(4): 337-344.

42. Abd El-Hamid, M.I., Awad, N.F., Hashem, Y.M., AbdelRahman, M.A., Abdelaziz, A.M., Mohammed, I.A. and Abo-Shama, U.H. (2019) In vitro evaluation of various antimicrobials against field Mycoplasma gallisepticum and Mycoplasma synoviae isolates in Egypt. Poult. Sci., 98(12): 6281-6288

43. Xiao, X., Sun, J., Yang, T., Fang, X., Cheng, J., Xiong, Y.Q. and Liu, Y.H. (2016) Pharmacokinetic/pharmacodynamic profiles of tiamulin in an experimental intratracheal infection model of Mycoplasma gallisepticum. Front. Vet. Sci., 3: 75.

44. Hong, Y.H., Kwon, J.S., Lee, H.J., Song, C.S. and Lee, S.W. (2015) Eradication of Mycoplasma synoviae from a multiage broiler breeder farm using antibiotics therapy. Poult. Sci., 94(10): 2364-2368. 